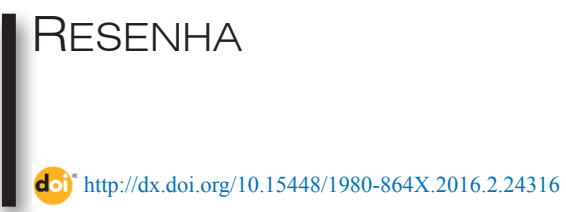

\title{
Os muitos tempos de Leonel Brizola
}

\author{
The many times of Leonel Brizola \\ Los muchos tiempos de Leonel Brizola
}

Charles Sidarta Machado Domingos*

\section{RESENHA DE:}

FREIRE, Américo; FERREIRA, Jorge. A razão indignadaLeonel Brizola em dois tempos (1961-1964 e 1979-2004). Rio de Janeiro: Civilização Brasileira, 2016.

Movimento. Ideologia. Projeto político. Tradição política. Cultura política. O trabalhismo, no Brasil, já foi, e ainda é interpretado conceitualmente de diversas formas. Até mesmo sob as vestes de populismo ele foi analisado, por largo tempo. Contudo, a despeito da concepção teórica empregada, há pontos que parecem já pacificados entre nós, historiadores, pelo menos: que ele, o trabalhismo, teve início ao final da ditadura do Estado Novo; e que foi "inventado" por assim dizer, com o objetivo de se constituir em uma alternativa, para os trabalhadores, ao comunismo - onde é possível traçar um paralelo com a criação do Estado de Bem-Estar Social na Europa como alternativa para o comunismo de matiz soviética (HOBSBAWM, 2003, p. 17).

Embora tenha variações ao longo do tempo, o trabalhismo brasileiro esteve sempre ancorado em algumas noções fundamentais:

* Professor de História no Instituto Federal de Educação, Ciência e Tecnologia Sul-rio-grandense (IFSUL - Câmpus Charqueadas)<csmd@terra.com.br> 
a incorporação das camadas trabalhadoras ao sistema capitalista com algum grau de redistributivismo social; o nacionalismo e a defesa da soberania do país; e a busca por participação política nos marcos da democracia. Um ponto importante de inflexão no trabalhismo do Partido Trabalhista Brasileiro (PTB) foi o suicídio do presidente Getúlio Vargas Com a ausência do principal líder do partido, disputas internas estabeleceram novas dinâmicas no trabalhismo, propiciando um espaço maior para propostas reformistas ou mesmo revolucionárias, ambas de corte predominantemente nacionalista (DELGADO, 1989; GOMES; 1994; D’ARAÚJO, 1996).

Dentro dessa guinada reformista, a melhor expressão foi João Goulart. Seu projeto político pode ser descrito como tendo caráter nacional-reformista em razão de pugnar a interferência do Estado na realização de reformas sociais, políticas e econômicas, visando ao desenvolvimento do país. Para este fim, medidas importantes foram a sistematização da Política Externa Independente - que tinha como um dos preceitos fundamentais o desenvolvimento econômico a partir das relações internacionais do Brasil no contexto da Guerra Fria -, a criação do $13^{\text {o }}$ salário, o "Estatuto do Trabalhador Rural" - que levava os direitos sociais aos trabalhadores do campo -, a Lei da Remessa de Lucros (que limitava o envio de capitais para o exterior) e a criação da Eletrobrás (DOMINGOS, 2010, p. 83-92). No entanto, as condições políticas do início dos anos 60, tanto conjunturalmente como estruturalmente, permitiam sonhar - e lutar - por medidas mais radicais; embora não pretendessem, em momento algum, romper com os limites do capitalismo. E o nome capaz de unir essas propostas com características nacional-revolucionárias era o do trabalhista Leonel Brizola (FERREIRA, 2007, p. 546-555).

As razões para o Golpe de 64 ainda não são ponto pacífico na historiografia. Todavia, a evolução do trabalhismo, pendendo cada vez mais para a esquerda, seja reformista seja revolucionária, é um dos pontos capazes de explicar - de forma isolada ou em conjunto com outros fatores, como o anticomunismo, a exaustão do modelo de acumulação do capital, os interesses externos - os motivos que solaparam a democracia no Brasil naquele tempo de ontem. Muito já tem se escrito sobre o Golpe de 64 e sobre o governo João Goulart. Contudo, fazia falta um livro que se dedicasse a um dos personagens mais importantes do trabalhismo brasileiro; afinal, se a proposição de Marc Bloch se mantém correta e "a História é a ciência que estuda os homens no tempo" (BLOCH, 2001, p. 55), uma obra que analisasse a 
dimensão histórica de Leonel Brizola ao longo do tempo era mais do que necessária - era urgente.

A Razão Indignada - Leonel Brizola em dois tempos (1961-1964 e 1979-2004) é uma obra coletiva produzida por importantes historiadores brasileiros e organizada pelos Professores Américo Freire do CPDOC-FGV e Jorge Ferreira da UFF. Enfatizando a figura de Brizola sem descontextualizá-la de suas épocas e do seu papel no trabalhismo, as autoras e os autores do livro estabelecem reflexões oportunas sobre a História do Brasil na segunda metade do século XX.

O livro conta com análises aprofundadas sobre a conformação do ideário político de Brizola, realizada pelo Professor Jorge Ferreira. Para o autor, Brizola compreendia "o trabalhismo à luz das idéias que empolgavam as esquerdas na América Latina desde meados dos anos 1950, influenciado pelos movimentos anti-imperialistas latinoamericanos na conjuntura da Guerra Fria e pelas repercussões da revolução cubana" (FREIRA; FERREIRA, 2016, p. 23) ${ }^{1}$. Analisando as palestras realizadas por Leonel Brizola no início dos anos 60, o professor Ferreira destaca a importância que determinadas ideias tiveram sobre a orientação política do líder petebista; em especial, o nacionalismo de corte anti-imperialista com a crítica veemente à deterioração dos temos de troca e o processo espoliativo ao qual o país vinha sendo submetido. Segundo o autor, a apropriação elaborada por Brizola sobre essas idéias era o elemento aglutinador de sua liderança perante as esquerdas revolucionárias do período.

As Professoras Carla Brandalise e Marluza Marques Harres abordam, em capítulo fartamente documentado, os Comandos Nacionalistas, também conhecidos como Os Grupos de 11. A análise das Professoras Brandalise e Harres está centrada principalmente, mas mão só, em entender quem eram os "seus adeptos de base e dos motivos dessa adesão" (FREIRE; FERREIRA, 2016, p. 53) no estado do Rio Grande do Sul. Além disso, as autoras se questionam a respeito do teor do movimento: seriam Os Grupos de 11 agrupamentos armados com vistas à ação de tomada do poder ou seriam a tentativa de formação de um grupo organizado para reagir ao golpismo?

A primeira parte do livro ainda conta com os artigos da Professora Tânia dos Santos Tavares, da Professora Soanne Cristino Almeida dos Santos e do Professor Gabriel da Fonseca Onofre. A Professora

${ }^{1}$ As referências à obra constantes nessa resenha serão todas feitas como FREIRE; FERREIRA, 2016, sendo os autores dos capítulos referidos no corpo do texto. 
Tânia Tavares também aborda Os Grupos de 11, porém, a partir dos depoimentos de pessoas que participaram daquele movimento na cidade de Duque de Caxias, no Rio de Janeiro. A Professora Soanne dos Santos está preocupada em entender como a Frente de Mobilização Popular se organizou na cidade de Una, na Bahia. Já o Professor Gabriel Onofre aborda a tensa relação no interior do PTB entre os grupos de Leonel Brizola e San Tiago Dantas na busca pela hegemonia partidária e capacidade de influência no governo Goulart.

Se na primeira parte do livro as análises estão mais bem distribuídas geograficamente, na segunda parte do livro o eixo de análise é o estado do Rio de Janeiro, onde Leonel Brizola foi eleito governador em duas ocasiões. Seu retorno ao Brasil, a implementação de suas políticas de segurança e de educação pública, a refundação do trabalhismo e a rivalidade no campo da esquerda com o Partido dos Trabalhadores (PT) são o mote dessa segunda seção.

Em seu artigo, o Professor Américo Freire analisa como se deu o retorno de Leonel Brizola do exílio para o Brasil, se preocupa em entender como o importante líder das esquerdas nos anos 60 redimensiona seu discurso político-ideológico para os novos tempos e investiga, ainda que preliminarmente, a participação do agora ex-governador do Rio de Janeiro nas eleições presidenciais de 1989 e 1998. Ao longo do trabalho, o Professor Freire traz elementos que demonstram como foi se desenvolvendo a rivalidade entre o Partido Democrático Trabalhista (PDT) e o PT ao longo das décadas de 80 e 90 no campo das esquerdas. Enquanto o PDT se colocava como "herdeiro direto do 'velho trabalhismo' dos tempos do 'Dr. Getúlio"”, sendo eles, os trabalhistas os que "'vinham de longe' e representavam, nada mais, nada menos, do que o 'fio da História' das lutas do povo brasileiro contra a injustiça e a opressão perpetradas pelas elites" o PT pretendia se afirmar "buscando se desvencilhar dos erros históricos das esquerdas e afirmando-se como algo novo, como um 'fenômeno político' verdadeiramente democrático e capaz de reunir a classe trabalhadora em torno de um projeto próprio de poder" (FREIRE; FERREIRA, 2016, p. 203).

O compromisso com a Educação Pública foi uma das maiores marcas de Brizola, nos seus dois tempos. E essa é a temática do artigo da Professora Libânia Xavier, que analisa o impacto social e as controvérsias ocasionadas a partir da construção das Brizoletas no Rio Grande do Sul nos anos 60 e dos Brizolões no Rio de Janeiro nos anos 80 e 90 . E de acordo com a Professora Xavier, o projeto educacional 
de Brizola sofreu e ainda sofre muita oposição e resistência no Rio de Janeiro, onde ela menciona uma reportagem de jornal do ano de 2006 que questiona se "o custo do aluno do Ciep vale a pena?" ao trazer o exemplo de um aluno da primeira turma que naquele momento estava detido na penitenciária de Bangu III. Na análise da Professora, essa pergunta, naquele contexto da reportagem, "induz o leitor a avaliar como um desperdício o ato de investir dinheiro público na tentativa de educar pessoas que, de acordo com certa visão de mundo, estariam condenadas ao crime e a marginalidade" (FREIRE; FERREIRA, 2016, p. 285). Para a Professora Xavier, a análise dos dois tempos de Leonel Brizola na política brasileira comprova que ele "adotou uma postura convicta a respeito da centralidade da educação em seu projeto de construção de uma sociedade democrática entre nós" (FREIRE; FERREIRA, 2016, p. 288).

O Professor Bruno Marques Silva, analisa, em sua contribuição ao livro, a política de segurança pública nos governos de Brizola no Rio de Janeiro. Para o Professor Silva, a grande inovação - e, portanto, alvo de muitas polêmicas - foi a busca pela modernização do sistema de segurança tributário do período ditatorial. Para o Professor, o problema central esteve relacionado a tentativa de se buscar "uma reforma conciliatória, redefinindo a cultura institucional, mas preservando sua estrutura organizacional militar" (FREIRE; FERREIRA, 2016, p. 259).

O funeral de Leonel Brizola, em 21 de junho de 2004, foi o ponto de partida da reflexão da Professora Angela de Castro Gomes: "os funerais são cerimônias que podem se transformar em rituais cívicos, nos quais o que se cultua, por excelência, é a pátria, ali representada pela pessoa do morto ilustre" (FREIRE; FERREIRA, 2016, p. 302). O nacionalismo, componente intrínseco do trabalhismo, parece manter-se, ou mesmo reforçar-se, com a morte daqueles que o utilizaram em sua constituição de visão de mundo.

Não foram poucos os analistas, seja da grande imprensa, seja nos meios acadêmicos, que viram na morte de Brizola o fim de uma era. $\mathrm{O}$ jornal $O$ Globo, do Rio de Janeiro, editou um caderno especial no dia 23 de junho de 2004 com esse título. Muito rapidamente, essa assertiva se tornou poderosa, criando uma espécie de lugar-comum, estabelecendo certo consenso inclusive. Contudo, a Professora Michelle Reis de Macedo, em seu artigo sobre as relações das esquerdas revolucionárias (PCB e PC do B) com o emergente PDT na década de 80, questiona essa afirmação. Para a Professora Macedo, a morte de Brizola não representa 
o fim de uma era. Ao analisar as características presentes em Brizola que possibilitaram essa conclusão "sua performance carismática na comunicação com os trabalhadores, o que muitas vezes se reverteu em vitórias eleitorais" (FREIRE; FERREIRA, 2016, p. 235) a autora aponta que o ex-presidente Lula também tem essas características; portanto, não se poderia falar em fim de uma era.

Ocorre, contudo, uma reflexão final. Leonel Brizola foi um dos maiores políticos brasileiros da segunda metade do século - isso parece inegável, por mais polêmico que tenha sido. Suas vitórias eleitorais atestam isso: deputado estadual no Rio Grande d Sul (1946 e 1950), deputado federal pelo Rio Grande do Sul (1954), prefeito de Porto Alegre (1955), governador do Rio Grande do Sul (1959), deputado federal pela Guanabara eleito com a maior votação do país (1962), duas vezes eleito governador do Rio de Janeiro (1983 e 1990). Após sua última vitória, contudo, sofreu reveses bastante significativos nas eleições presidenciais de 1994 (quinto lugar), eleições para a prefeitura do Rio de Janeiro de 2000 (quarto lugar), eleição para o senado pelo Rio de Janeiro em 2002 (sexto lugar). Seu tempo de conquistas e de realizações foi no mundo que conheceu: o tempo da Guerra Fria (1945-1991). Mesmo com as mudanças que aconteceram no interior da Guerra Fria, Brizola ainda conseguia se reinserir na vida política. O fim da Guerra Fria foi o fim do mundo que Brizola conhecia: e no desconhecido, não soube mais se recolocar no mundo.

\section{Referências}

BLOCH, Marc. Apologia da História ou o oficio de historiador. Rio de Janeiro: Zahar, 2001.

D'ARAUJO, Maria Celina. Sindicatos, carisma e poder. O PTB de 1945-1965. Rio de Janeiro: Editora FGV, 1996.

DELGADO, Lucília de Almeida Neves. PTB: do getulismo ao reformismo (1945-1964). São Paulo: Marco Zero, 1989.

DOMINGOS, Charles Sidarta Machado. O Brasil e a URSS na Guerra Fria: a Política Externa Independente na imprensa gaúcha. Porto Alegre: Suliani Letra \& Vida, 2010 .

FERREIRA, Jorge. Leonel Brizola, os nacional-revolucionários e a Frente de Mobilização Popular. In: FERREIRA, Jorge; REIS, Daniel Aarão. Nacionalismo e reformismo radical. Rio de Janeiro: Civilização Brasileira, 2007.

FREIRE, Américo; FERREIRA, Jorge. A Razão Indignada - Leonel Brizola em dois tempos (1961-1964 e 1979-2004). Rio de Janeiro: Civilização Brasileira, 2016. 
GOMES, Angela de Castro (Org.). Vargas e a crise dos anos 50. Rio de Janeiro: Relume-Dumará, 1994.

HOBSBAWM, Eric. Era dos Extremos - O breve século XX (1914-1991). São Paulo: Companhia das Letras, 2003.

Recebido: 13 de junho de 2016 Aprovado: 04 de julho de 2016

\section{Autor/Author:}

CHARLES SIDARTA MACHADO DOMINGOS <csmd@terra.com.br $>$

- Doutor em História pela Universidade Federal do Rio Grande do Sul (UFRGS). Professor de História no Instituto Federal de Educação, Ciência e Tecnologia Sul-rio-grandense (IFSUL - Câmpus Charqueadas). Autor de O Brasil e a URSS na Guerra Fria: a Política Externa Independente na Imprensa Gaúcha. (Letra \& Vida, 2010). Especialista em temas da História do Século XX como História do Brasil Contemporâneo com ênfase no Tempo da Experiência democrática (1946-1964), Guerra Fria, Ditadura civil-militar no Brasil.

- $\mathrm{PhD}$ in History from the Federal University of Rio Grande do Sul (UFRGS). Professor of History at the Instituto Federal de Edecação, Ciência e Tecnologia Sul-rio-grandense (IFSUL - Câmpus Charqueadas). Author of O Brasil e a URSS na Guerra Fria: a Politica Externa Independente na Imprensa Gaúcha. (Letra \& Vida, 2010). He is specialist in the History of Contemporary Brazil, with emphasis on Brazil's first democratic experience (1946-1964), the Cold War, and the Civil-military Dictatorship in Brazil. 